\title{
HISTOPATOLOGIA DE BRÂNQUIAS DE PARALICHTHYS ORBIGNYANUS (TELEOSTEI: PARALICHTHYIDAE) PARASITADO POR THERODAMAS FLUVIATILIS (COPEPODA: ERGASILIDAE).
}

\author{
ANA LUIZA VELLOSO ${ }^{1,3}$, FRANCIS DE MATTOS ALMEIDA ${ }^{1,3}$, JOÃO C. B. COUSIN ${ }^{1,2,3}$ \& JOABER PEREIRA JR. ${ }^{1,3}$ \\ ${ }^{1}$ Universidade Federal do Rio Grande - Instituto de Ciências Biológicas - Laboratório de Biologia de Parasitos de Organismos Aquáticos - \\ Caixa Postal: 474, 96201-900 - Rio Grande - RS, Brasil. - ${ }^{2}$ Laboratório de Morfologia Funcional - ${ }^{3}$ Instituto de Oceanografia - PPG Aquicultura. \\ analuizavelloso@yahoo.com.br
}

\section{RESUMO}

Este trabalho avaliou as alterações branquiais provocadas pela presença de fêmeas adultas de Therodamas fluviatilis em Paralichthys orbignyanus capturados no Estuário da Lagoa dos Patos e costa adjacente, Rio Grande do Sul, Brasil. Macroscopicamente, os parasitos estavam parcialmente recobertos por uma reação tecidual do hospedeiro. A análise histopatológica mostrou modificação no epitélio das lamelas primárias e secundárias dos filamentos branquiais contíguos ao corpo dos copépodes, com possível alteração da função respiratória. A presença do copépode e a reação tecidual com forte infiltração linfocitária causam pressão sobre os tecidos adjacentes e estrangulamento da parede da artéria branquial. Além disso, verificou-se que $T$. fluviatilis armazena ovócitos no interior do tronco, sugerindo um grande potencial patogênico desse parasito. Um aumento na intensidade de infestação desses parasitos é esperado em condições de cultivo. Portanto, devido à patogenicidade de $T$. fluviatilis, se deve atentar para sua presença quando em condições de cultivo, evitando possíveis perdas econômicas.

PALAVRAS CHAVE: Linguado, Ectoparasita, Patologia, Aquicultura, Estuário da Lagoa dos Patos

\section{ABSTRACT}

Histopathology of the gills of Paralichthys orbignyanus (Teleostei: Paralichthyidae) associated with the parasitism of Therodamas fluviatilis (Copepoda: Ergasilidae)

This study evaluated changes in gill tissue caused by the presence of adult females of Therodamas fluviatilis in Paralichthys orbignyanus caught in the estuary of Patos Lagoon and the adjacent coast, Rio Grande do Sul, Brazil. Macroscopically, the parasites bodies were partially covered by a host tissue reaction. Complete histological series of the flatfish branchial arches were analyzed. Histological analysis showed modified filaments contiguous to the copepods bodies, with possible decrease of the respiratory function. A connective and epithelial hyperplasic reaction marked in the branchial arch involves the parasite anterior end. Both, the presence of copepod and the tissular reaction with massive lymphocytic infiltration, make pressure on the adjacent tissue, narrowing the wall of branchial artery. Moreover, it was found stored ovocytes inside the cephalothorax of $T$. fluviatilis. An increase in the intensity of the infestation of such parasites is expected under cultivation conditions. Therefore special attention should be paid towards the presence of $T$. fluviatilis in cultivation due to its pathogenicity to avoid possible economic losses.

KEYWORDS: Flatfish, Ectoparasite, Pathology, Aquaculture, Estuary of Patos Lagoon

\section{INTRODUÇÃO}

Os ectoparasitos mais comuns de peixes marinhos são os crustáceos pertencentes à ordem Copepoda (Dezfulli et al. 2010). Esses crustáceos parasitas causam danos tanto em peixes cultivados como selvagens (Costello 2006). Eiras (1994) postula que os danos causados por crustáceos parasitas nos peixes podem ser prejudiciais tanto pela sua presença, devido à pressão causada nos tecidos do hospedeiro, como por sua fixação, gerando importantes efeitos pela ação mecânica. Além disso, a alimentação à custa do hospedeiro causa danos que podem ser locais ou generalizados, dependendo do tipo de ação espoliativa do parasito (Eiras 1994). Kabata (1970) mostra importantes efeitos nas brânquias, que podem ser danificadas ou ter sua eficiência respiratória reduzida pela presença desses parasitos. Com isso, é possível ocorrer oclusão temporária ou permanente da circulação branquial, o que pode conduzir a necrose ou desintegração do tecido. A ocorrência de surtos de doenças por ergasilídeos está entre as principais causas de mortalidade induzida por copépodes, tanto em pisciculturas de água doce como salobra, em muitos países (Johnson et al. 2004).

Entre os muitos crustáceos parasitas de peixes, os copépodes são os que causam maiores prejuízos aos hospedeiros e, por isso, podem ser considerados como gravemente patogênicos (Sindermann 1990). Segundo Kabata (1970), os efeitos da parasitose podem ser divididos em duas fases: (1) invasão e fixação, resultando na destruição e deslocamento dos tecidos e (2) alimentação, resultando em perda de sangue. Esses efeitos podem induzir o hospedeiro a perda de peso, anorexia, redução da taxa de crescimento e, eventualmente, morte (Roberts et al. 2004).

Os copépodes parasitas têm importância econômica especialmente em peixes cultivados, pois o tratamento dos hospedeiros é difícil, sobretudo, quando os parasitos têm órgãos de fixação agressivos (Eiras 1994). Os ergasilídeos parasitam brânquias de muitas 
espécies de peixes, tanto de ambientes dulceaquícolas como salobros (Roberts 1979). A principal particularidade desses copépodes é a pronunciada modificação das antenas em fortes ganchos, que permitem sua fixação ao hospedeiro (Eiras 1994). Alterações histológicas em brânquias, causadas pela ação de ergasilídeos, têm sido estudadas por vários autores (Paperna \& Zwerwer 1982; Thatcher \& Boeger 1983a, 1983b; Thatcher 1986; Amado \& Rocha 1996; Molnár \& Székely 2004; Tsotetsi et al. 2005; Feist \& Longshaw 2008; Andrews et al. 2010; Dezfulli et al. 2011). Além dos danos branquiais, podem favorecer infecções secundárias (Feist \& Longshaw 2008).

Therodamas fluviatilis Paggi, 1976 (Copepoda: Ergasilidae) foi encontrado parasitando brânquias de Paralichthys orbignyanus (Valenciennes, 1839) (Teleostei: Paralichthyidae) no estuário da Lagoa dos Patos, Rio Grande, RS - Brasil (Velloso et al. 2005). As fêmeas adultas de Therodamas são mesoparasitas (ElRashidy \& Boxshall 2001) e todas as outras fases do desenvolvimento e os machos adultos são de vida livre (Boxshall \& Montú 1997). Por serem parasitos de brânquias, podem causar lesões importantes nos arcos e filamentos branquiais do hospedeiro, como mostrado em outros estudos (Andrews et al. 2010).

Paralichthys orbignyanus tem sido estudado com vistas ao cultivo. Esse linguado é tolerante as condições estressantes do estuário, apresentando um bom potencial para a aquicultura (Bianchini et al. 2005). Pesquisas sobre a fauna parasitária associada são fundamentais antes do estabelecimento da aquicultura comercial dessa espécie.

Neste estudo, são descritas as alterações histológicas das brânquias de $P$. orbignyanus provocadas pela parasitose de $T$. fluviatilis. $O$ conhecimento dessas alterações e as pesquisas sobre biologia do parasito poderão auxiliar no desenvolvimento de estratégias de controle da parasitose.

\section{MATERIAIS E MÉTODOS}

Cento e nove linguados, $P$. orbignyanus, foram obtidos junto a pescadores artesanais e à indústria local, provenientes do estuário da Lagoa dos Patos e costa adjacente. Desse total, foram encontradas 38 fêmeas de $T$. fluviatilis, em 30 espécimes de $P$. orbignyanus. Os índices parasitológicos de prevalência, intensidade média de infestação e abundância média foram calculados de acordo com Bush et al. (1997).

Dentro dessa amostra, foram selecionadas brânquias parasitadas por $T$. fluviatilis para análise histopatológica. As brânquias utilizadas foram extraídas e fixadas em formol $10 \%$ tamponado por 30 dias. Amostras de brânquias de linguados não parasitados também foram fixadas, para posterior comparação.

Após a fixação, os fragmentos branquiais (com e sem parasitos fixados) foram colocados em uma solução a $20 \%$ de EDTA (ácido etilenodiaminotetraacético) onde permaneceram durante 3 semanas, para promover a descalcificação. $\mathrm{Na}$ sequência, os tecidos foram desidratados em séries crescentes de álcool etílico; diafanizados em xilol; impregnados e incluídos em parafina.

Os cortes histológicos foram realizados em micrótomo rotativo American Optical, com espessura de $7 \mu \mathrm{m}$. Do material preparado a partir dos fragmentos branquiais parasitados, foram obtidas 85 lâminas histológicas e 400 cortes seriados, cobrindo as reações tissulares periféricas além de toda a extensão do corpo de T. fluviatilis.

Os cortes histológicos foram corados pela técnica de rotina Hematoxilina-Eosina, pelo Tricrômico de Mallory e ainda, submetidos à reação pelo Ácido Periódico - Schiff (APS). As lâminas foram analisadas em microscópio trinocular JENAMED 2 Carl Zeiss, e os casos selecionados foram fotomicrografados no mesmo equipamento.

\section{RESULTADOS}

Os índices parasitológicos indicam uma prevalência de $27,52 \%$. A intensidade de infecção varia de 1 a 3 parasitos por hospedeiro infectado. $\mathrm{Na}$ amostra total, foi obtida abundância média de 0,35 parasitos por hospedeiro amostrado.

As fêmeas adultas de $T$. fluviatilis encontradas nas brânquias de $P$. orbignyanus, acham-se firmemente aderidas aos arcos branquiais e não se desprendem com o manuseio e lavagem nos diferentes reagentes, durante 0 processamento histológico. Esses mesoparasitas têm na região cefálica um escudo, com um par de antenas, e excrescências usadas para ancoragem no tecido do hospedeiro. A região cefálica é seguida de uma porção semelhante a um pescoço, 
ligada com a região alargada, onde está a boca, formando o tronco. Esses crustáceos são detectados devido ao espaçamento que ocorre entre os filamentos branquiais, à formação de nódulos esbranquiçados e, ainda, à presença dos sacos ovígeros. Macroscopicamente, enquanto a região cefálica, o pescoço pré-oral e o tronco encontram-se parcialmente envoltos por uma massa acinzentada, os sacos ovígeros aparecem livres entre os filamentos.

A análise microscópica das séries histológicas de brânquias contendo os copépodes fixados permitiu caracterizar as principais reações teciduais e lesões que ocorrem nesse órgão, devido à infestação. A estrutura normal das brânquias (Figura 1), onde os filamentos mostram uma distribuição regular e uniforme das lamelas, não é observada nas regiões com presença dos parasitos (Figura 2). Nessas, os filamentos branquiais contíguos à região do corpo dos copépodes encontram-se com metaplasia mucinosa do epitélio respiratório (Figura 2).

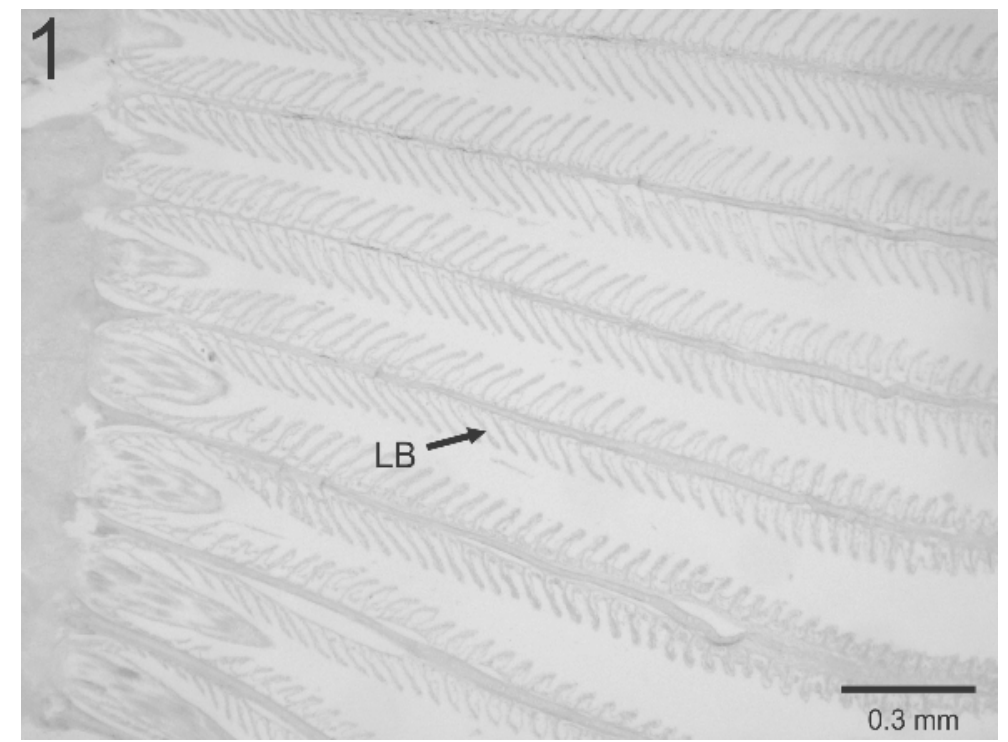

FIGURA 1 - Arco branquial de Paralichthys orbignyanus não parasitado, com estrutura histológica normal dos filamentos branquiais. Lamelas branquiais (LB). Col. Tricrômico de Mallory. Escala: 0,3 mm.

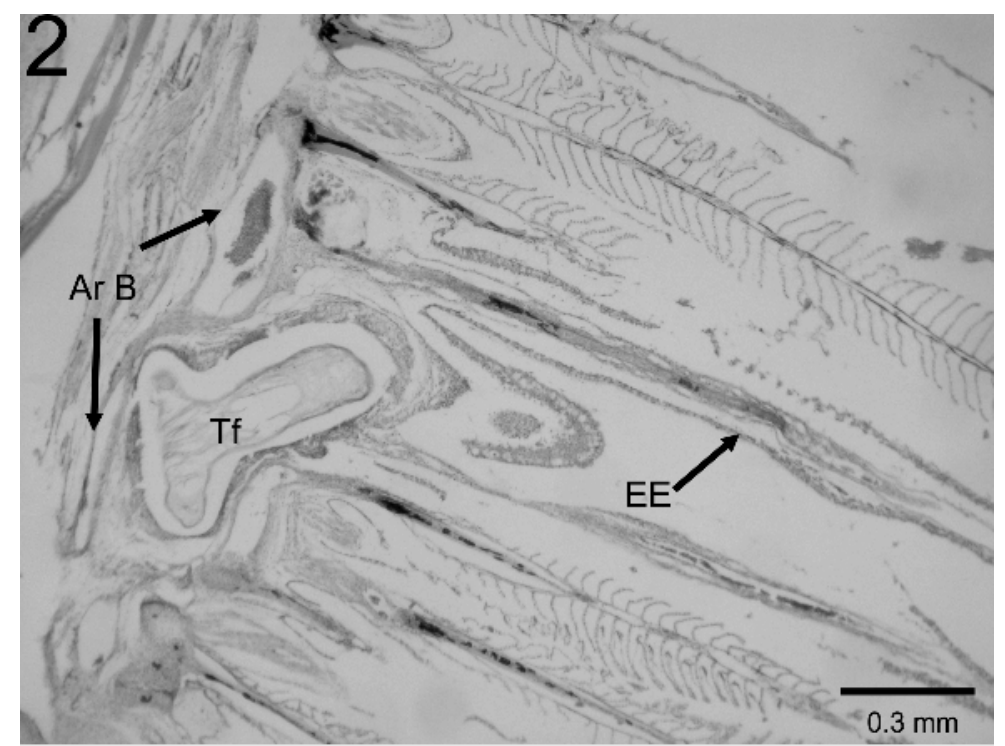

FIGURA 2 - Estrutura alterada do arco branquial de Paralichthys orbignyanus, devido à presença de Therodamas fluviatilis (Tf) circundado por marcada reação celular do hospedeiro. Artéria branquial (Ar B); Epitélio respiratório das lamelas primárias e secundárias transformado em Epitélio Estratificado (EE). Col. H.E. Escala: 0,3 mm.

A massa acinzentada, referida anteriormente, que envolve uma parte do corpo do copépode, é na realidade, uma reação epitelial hiperplásica do hospedeiro. Nesses locais ocorre proliferação 
acentuada de células epiteliais de revestimento e estratificado (Figura 3).

células mucosas que formam um espesso epitélio

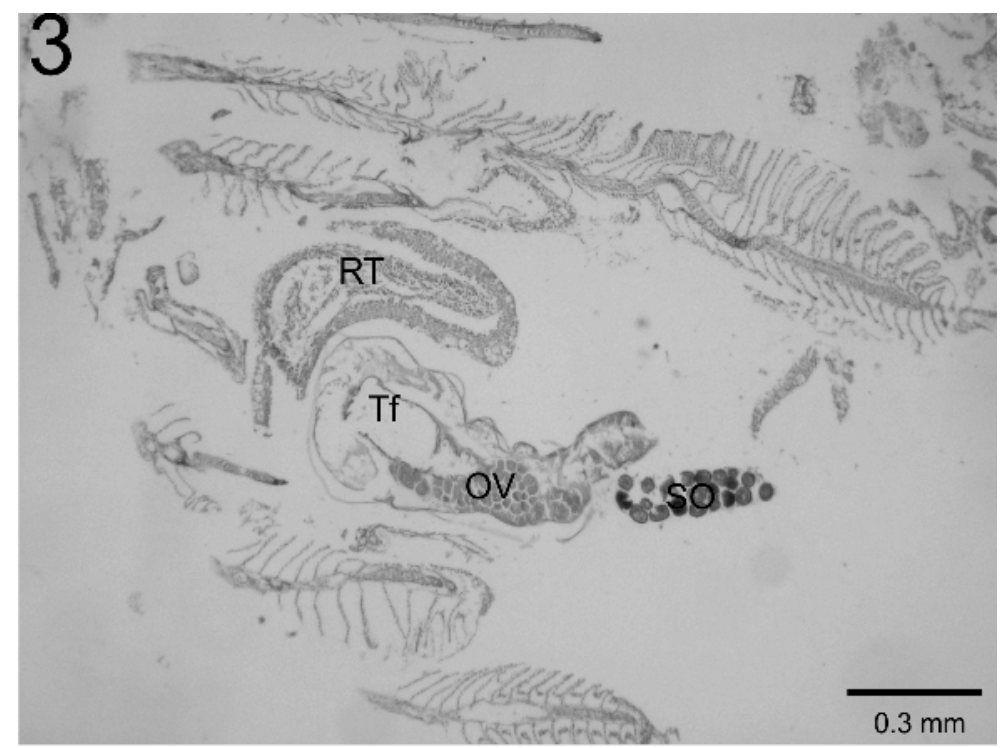

FIGURA 3 - Corte histológico de Therodamas fluviatilis (Tf), evidenciando ovócitos no interior do tronco (OV); saco ovígero (SO) entre os filamentos branquiais anormais e marcada reação tissular (RT) do hospedeiro, caracterizada pelo espesso epitélio estratificado com células mucosas. Col. H.E. Escala: $0,3 \mathrm{~mm}$.

A proliferação de tecido conjuntivo é acentuada no arco branquial, onde se encontram inseridas uma parte do pescoço pré-oral e a região cefálica de $T$. fluviatilis (Figura 4). Nesses locais, além da grande quantidade de fibroblastos, aparecem alguns macrófagos e infiltrados inflamatórios com predomínio de linfócitos. Entretanto, deve ser ressaltado que a presença de granulócitos (eosinófilos e neutrófilos) é bem discreta ou praticamente inexistente. Essa reação tecidual do hospedeiro que se forma ao redor da região cefálica do parasito, provoca pressão e estrangulamento da parede da artéria branquial (Figura 2), alterando a configuração de outras estruturas e tecidos da base dos filamentos e do próprio arco.

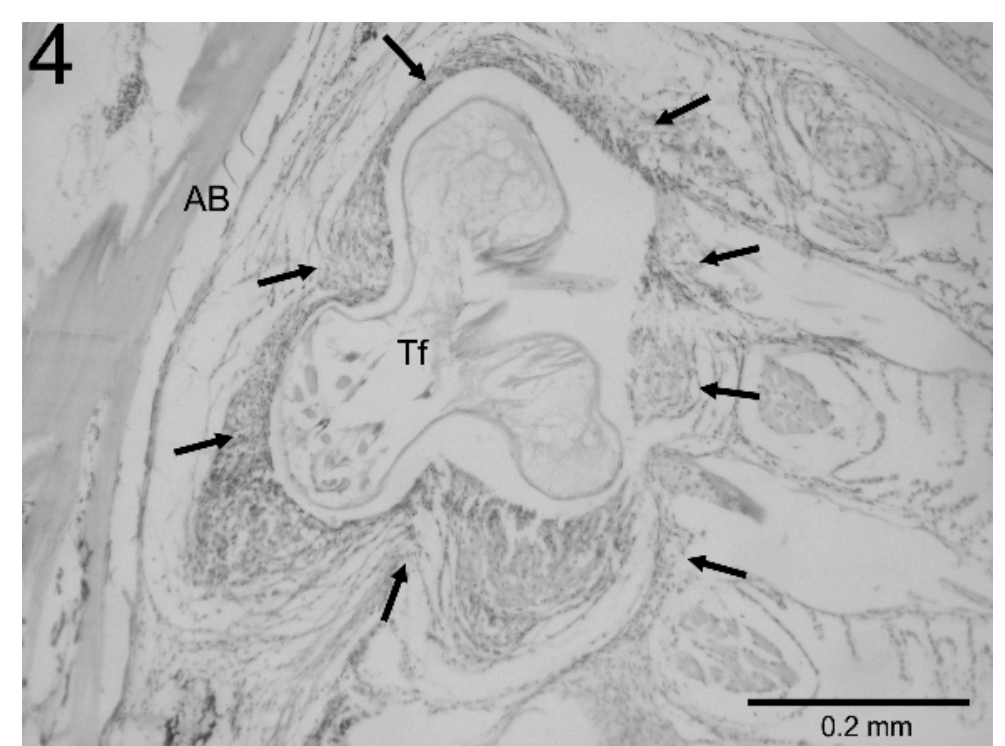

FIGURA 4 - Detalhe da região cefálica de Therodamas fluviatilis (Tf) fixado ao arco branquial (AB); Acentuada proliferação de tecido conjuntivo ao redor (setas). Col. H.E. Escala: 0,2 mm.

Além disso, pode ser verificado armazenam ovócitos no interior do tronco (Figura 3). histologicamente que fêmeas adultas de $T$. fluviatilis 


\section{DISCUSSÃO}

A fixação dos Ergasilidae nas brânquias pode causar oclusão parcial ou completa do vaso eferente das lamelas secundárias por trombose ou pressão, bem como fusão das lamelas, provocando redução da superfície respiratória (Eiras 1994). As análises histopatológicas das brânquias de $P$. orbignyanus mostraram reação tecidual do hospedeiro ao redor da região cefálica de $T$. fluviatilis, que provoca pressão e estrangulamento da parede da artéria branquial. Resultados semelhantes foram encontrados por Amado e Rocha (1996), ao observarem que $T$. elongatus se fixa perto da principal artéria do septo branquial, causando hiperplasia epitelial das lamelas primárias e secundárias. Da mesma forma, Thatcher (1986) postula que fêmeas de Therodamas spp. passam através dos tecidos flexíveis do arco branquial até alcançar o suporte cartilaginoso, onde se prendem fortemente com as antenas. Como a região cefálica penetra, a região do pescoço pré-oral alonga-se até que a parte posterior fique livre, entre os filamentos branquiais. Thatcher e Boeger (1983b) afirmam que os diferentes graus de patogenicidade dos Ergasilidae estão relacionados com os diversos modos de fixação nas brânquias.

A penetração da região cefálica de $T$. fluviatilis provoca uma reação no hospedeiro que estende uma massa epitelial ao longo de todo pescoço pré-oral (Thatcher 1986), o que também foi observado neste estudo. Thatcher (1986) e Amado e Rocha (1996) evidenciaram uma cápsula fibrosa envolvendo a região cefálica e a parte superior do pescoço pré-oral, da mesma forma que ocorre em $T$. fluviatilis. Porém, calcificação desse tecido, como observado por Thatcher (1986), não foi observada, corroborando Amado e Rocha (1996).

Os filamentos branquiais do peixe se tornam notavelmente transformados, com atrofias e dobras (Amado \& Rocha 1996). O epitélio respiratório das lamelas primárias e secundárias dos filamentos branquiais adjacentes ao ponto de inserção do parasito se transforma por metaplasia mucinosa em um epitélio estratificado com células mucosas. O aumento na quantidade de células mucosas também foi observado por Thatcher e Boeger (1983a) na reação provocada por Ergasilus colomesus parasita de Colomesus asellus. Essa transformação dos filamentos, provavelmente esteja ocorrendo pela ação mecânica da presença do copépode, pois os apêndices são muito pequenos em relação ao corpo para serem responsáveis pela abrasão dos filamentos branquiais, como sugerido por Thatcher (1986).

Fêmeas adultas de $T$. fluviatilis armazenam ovócitos no interior do tronco. Esse fato aponta para o grande potencial patogênico desse parasito, assim como alguns autores já têm demonstrado para outros copépodes (Whitfield et al. 1988; Robaldo et al. 2002; Thatcher \& Pereira Jr. 2004). Muitas vezes, para 0 tratamento da parasitose por copépodes tão agressivos como Therodamas spp., é necessário o emprego de produtos altamente tóxicos, que podem ter efeitos adversos para os hospedeiros e o ambiente (Stone et al. 2000). Outra forma de tratar a parasitose é a remoção manual dos parasitos. Roberts et al. (2004) comparam clínica e histologicamente esses dois tipos de tratamento, reconhecendo que a remoção manual do parasito é mais agressiva e menos eficaz para o hospedeiro. Estudos sobre tratamento e prevenção precisam considerar o ciclo de vida do parasito em questão e o sistema de cultivo dos hospedeiros. Perdas diretamente atribuídas ao parasito são geralmente baixas, mas causam problemas respiratórios que podem ser determinantes em momentos de estresse de oxigênio ou temperatura (Kabata \& Cousens 1973), fatores importantes na piscicultura.

Os resultados deste estudo mostram que a infestação por $T$. fluviatilis causa importantes danos ao epitélio respiratório de $P$. orbignyanus, além de obstruir a artéria do arco branquial. Em condições naturais, o prejuízo ao hospedeiro pode não parecer tão grave. Porém, em condições de cultivo, onde é esperado aumento na intensidade de infestação desses parasitos, os danos poderão ser mais intensos. Portanto, se deve atentar para a presença de $T$. fluviatilis, devido à sua patogenicidade.

\section{AGRADECIMENTOS}

Os autores agradecem ao apoio da FURG, FAPERGS, CNPq e CAPES; à colaboração do Téc. Lab. Pedro Antônio Garcia e da Biol. Emeline Gusmão (Laboratório de Morfologia Funcional ICB/FURG) no processamento do material histológico e ao Prof. Dr. Luis Alberto Romano, pelas valiosas sugestões. 


\section{REFERÊNCIAS}

AMADO, MAPM \& CEF ROCHA. 1996. Therodamas tamarae, a new species of copepod (Poecilostomatoida: Ergasilidae) parasitic on Plagioscion squamosissimus (Heckel) from the Araguaia River, Brazil; with a key to the species of the genus. Hydrobiol., 325: 77-82.

ANDREWS, M, S BATTAGLENE, J COBCROFT, M ADAMS, E NOGA \& B NOWAK. 2010. Host response to the chondracanthid copepod Chondracanthus goldsmidi, a gill parasite of the striped trumpeter, Latris lineata (Forster), in Tasmania. J. Fish Dis. 33: 211-220. doi:10.1111/j.1365-2761.2009.01107.x

BIANCHINI, A, RB ROBALDO \& LA SAMPAIO. 2005. Cultivo do linguado, Paralichthys orbignyanus. In: Baldisseroto $B$ and LC Gomes (ed.). Espécies nativas para a piscicultura no Brasil. Ed. da UFSM, Santa Maria, Cap. 20: 445-470.

BOXSHALL, GA \& MA MONTÚ. 1997. Copepods Parasitic on Brazilian Coastal Fishes: a Handbook. Nauplius, 5(1): 1-225.

BUSH, AO, KD LAFFERTY, JM LOTZ, AW SHOSTAK. 1997. Parasitology meets ecology on its own terms: Margolis et al. Revisited. J. Parasitol., 83 (4): 575-583.

COSTELLO, MJ. 2006. Ecology of sea lice parasitic on farmed and wild fish. Trends Parasitol. 22: 475-483.

DEZFULLI, BS, S SQUERZANTI, S FABBRI, G CASTALDELLI \& L GIARI. 2010. Cellular response in semi-intensively cultured sea bream gills to Ergasilus sieboldi (Copepoda) with emphasis on the distribution, histochemistry and fine structure of mucous cells. Vet. Parasitol. 174: 359-365. doi:10.1016/j.vetpar.2010.08.024

DEZFULLI, BS, L GIARI, A LUI, M LORENZONI \& EJ NOGA. 2011. Mast cell responses to Ergasilus (Copepoda), a gill ectoparasite of sea bream. Fish Shellfish Immunol. 30: 1087-1094. doi:10.1016/j.fsi.2011.02.005

EIRAS, JC. 1994. Elementos de Ictioparasitologia. Porto, Fundação Eng. António de Almeida. 339 p.

EL-RASHIDY, H \& GA BOXSHALL. 2001. Ergasilid copepods (Poecilostomatoida) from the gills of primitive Mugilidae (grey mullets). Syst. Parasitol., 42: 161-186.

FEIST, SW \& M LONGSHAW. 2008. Histopathology of fish parasite infections - importance for populations. J. Fish Biol. 73: 21432160. doi:10.1111/j.1095-8649.2008.02060.x

JOHNSON, SC, JW TREASURER, S BRAVO, K NAGASAWA \& Z KABATA. 2004. A review of the impact of parasitic copepods on marine aquaculture. Zool. Studies 43: 229-243.

KABATA, Z. 1970. Crustacea as Enemies of Fishes. T.F.H. Publications, USA, 171p.

KABATA, Z \& B COUSENS. 1973. Life cycle of Salmincola californiensis (Dana 1852) (Copepoda: Lerneaopodidae). J. Fish. Res. Board Canada, 30: 881-903.

KABATA, Z. 1979. Parasitic Copoepoda of British Fishes. London: The Ray Soc. \& Brittish Museum Ed., 468P.

MOLNÁR, K \& CS SZÉKELY. 2004. Occurrence and pathology of Sinergasilus lieni (Copepoda: Ergasilidae), a parasite of the silver carp and bighead, in Hungarian ponds. Acta Vet. Hung. 52: 51-60.

PAPERNA, IE \& DE ZWERNER. 1982. Hostparasite relationship of Ergasilus labracis Krøyer (Cyclopidea, Ergasilidae) and the striped bass, Morone saxatilis (Walbaum) from the lower
Chesapeake Bay. Ann. Parasitol. Hum. 57: 393-405.

ROBALDO, RB, J PEREIRA JR., LAN SAMPAIO, VT KÜTTER \& A BIANCHINI. 2002. Ovoposição e desenvolvimento inicial de Caligus sp. (Copepoda: Caligidae) parasita de juvenis do linguado Paralichthys orbignyanus (teleostei: Paralichthyidae) em cativeiro. Atlântica, 24(2): 31-34.

ROBERTS, RJ. 1979. Pathologie du poisson. Maloine S.A. Editeur, Paris, 317p.

ROBERTS, RJ, KA JOHNSON \& MT CASTEN. 2004. Control of Salmincola californiensis (Copepoda: Lerneaopodidae) in rainbow trout, Onchorhynchus mykiss (Walbaum): a clinical and histopathological study. J. Fish Dis., 27: 73-79.

SÃO CLEMENTE, SC, E MATOS, R TORTELLY \& FC LIMA. 1998. Histopathology of the parasitism by metacercaries of Clinostomum sp. in Tamoata, Hoplosternum littorale (Hancock, 1828). Parasitol. día, v.22 n.1-2

SINDERMANN, CJ. 1990. Principal disease of marine fish and shellfish. vol.1.2.ed. Academic Press, Inc, San Diego, California. $535 \mathrm{p}$.

STONE, J, IH SUTHERLAND, C SOMMERVILLE, RH RICHARDS \& KJ VARMA. 2000. Field trials to avaluate the efficacy of emamectin benzoate in the control of sea lice, Lepeophtheirus salmonis (Krøyer) and Caligus elongates Nordmann, infestation in Atlantic salmon Salmo salar L. Aquaculture, 186: 205-219.

THATCHER, VE \& WA BOEGER. 1983a. The parasitic crustaceans of fishes from the Brazilian Amazon, 4, Ergasilus colomesus $\mathrm{n}$. sp. (Copepoda: Cyclopoida) from an Ornamental Fish, Colomesus asellus (Tetraodontidae) and Aspects on its Pathogenicity. Trans. Am. Microsc. Soc., 102(4): 371-379. 1983.

THATCHER, VE \& WA BOEGER. 1983b. Patologia de peixes da Amazônia, 3, Alterações histológicas em brânquias provocadas por Ergasilus, Brasergasilus e Acusicola (Crustacea: Cyclopoida: Ergasilidae). Acta Amazônica, 13(2): 441-451.

THATCHER, VE. 1986. The parasitic crustaceans of fishes from the Brazilian Amazon, 16, Amazonicopeus elongatus gen. et sp. nov. (Copepoda: Poecilostomatoida) with the proposal of Amazonicopeidae fam. nov. and remarks on its pathogenicity. Amazoniana, 10: 49-56.

THATCHER, VE, J PEREIRA JR. 2004. Brasilochondria riograndensis gen. et sp. n. (Copepoda, Poecilostomatoida, Chondracanthidae) a parasite of flounder of Rio Grande do Sul, Brasil. Rev. Brasil. Zool. 21(3): 515-518.

TSOTETSI, AM, A AVENANT-OLDEWAGE \& SN MASHEGO. 2005. Aspects of the pathology of Lamproglena clariae (Copepoda: Learnaeidae) of gills of Clarias gariepinus from the Vaal River system, South Africa. Afr. Zool. 40:169-178.

VELLOSO, AL, J PEREIRA JR. \& JCB COUSIN. 2005. Therodamas fluviatilis (Copepoda: Ergasilidae), parasito de Paralichthys orbignyanus (Teleostei: Paralichthyidae) do Estuário da Lagoa dos Patos e costa adjacente, RS, Brasil. Bol. Inst. Pesca São Paulo, 31: 65-71.

WHITFIELD, PJ, MW PILCHER, HJ GRANT \& J RILEY. 1988. Experimental studies on the development of Lernaeocera branchialis (Copepoda: Pennellidae): population processes from egg production to maturation on the flatfish host. Hydrobiol., 167/168:579-586. 